\title{
Effect of high levels of incorporation of spring peas into maize or barley based diets and as a supplement of rapeseed meal
}

\author{
J. CASTAING *, F. GROSJEAN ** \\ *A.G.P.M., 122, boulevard Tourasse, 64000 Pau \\ ** I.T.C.F., 8, avenue du Président-Wilson, 75116 Paris
}

\begin{abstract}
Utilization of spring peas by the bacon pig between 25 and $100 \mathrm{~kg}$ was studied in 2 trials. In both trials 48 castrated males and 48 females of the Large White breed were tested in restricted feeding conditions. In the 1 st trial diets including $0-20-25$ or 30 p. 100 peas were compared to determine the maximum level of incorporation into diets based on barley and soyabean. In the second trial, the association of spring peas with rapeseed meal, was studied. The rapeseed meal was originated from simple 0 seeds, but exhibited very low glucosilonate contents $(34.8 \mathrm{moles} / \mathrm{g}$ DM) because of a double toasting. The peas and rapeseed meal levels of the 4 diets were 0 and 0,25 and 0,0 and 8 and 25 and 8 , respectively.

In the 1st trial made during the growing period. diets including 25 and 30 p. 100 peas led to lower performances than the others. During the finishing period, the 4 diets led to similar performances, so that the 4 diets led to the same results over the whole fattening period. As regards the carcass and fatness, results were identical whatever the diet. In the second trial, during the growing period, the diet including 25 p. 100 peas without rapeseed meal led to lower performances than the other three diets. This difference was smaller during the finishing period so that growth performances were the same with the 4 diets over the whole fattening period. The two diets including rapeseed meal led to a slight increase in liver weight $(140 \mathrm{~g})$. This did not affect the carcass yield. The carcass quality was nearly the same whatever the diet.
\end{abstract}

\section{Long term effects of the level of feeding between 10 and $25 \mathrm{~kg}$ live weight on pig growth performance and body composition}

\author{
B. SEVE, J.M. PEREZ, B. DESMOULIN \\ I.N.R.A., Station de Recherches sur l'Elevage des Porcs, \\ Saint-Gilles, 35590 L'Hermitage
}

\begin{abstract}
A factorial experiment $2^{3}$ ( 3 factors at 2 levels) involving 96 pigs was performed in order to assess the effects of sex and feed restrictions at two successives stages (10 to $27 \mathrm{~kg}$ live weight $(\mathrm{LW})=\mathrm{A}_{1}$; or 27 to $\left.101 \mathrm{~kg} \mathrm{LW}=\mathrm{A}_{*}\right)$ on growth rate, feed conversion ratio and lean meat production. The 2 nd $\left(S \times A_{1} \times A_{2}\right)$ and the 1st order interactions between the 2 restriction stages $\left(A_{1} \times A_{2}\right)$ were not significant.

At stage $\mathbf{A}_{1}$, ad libitum fed females were less efficient than castrated males in terms of daily weight gain $(562$ vs $597 \mathrm{~g} /$ day, $\mathrm{P}<0.10)$ and feed conversion ratio $(1.93$ vs 1.77 , $\mathrm{P}<0.01$ ). The feed restriction, $23.5 \mathrm{p}$. 100 on average, reduced the growth rate but cancelled the differences between sexes by increasing the feed efficiency in gilts. No effect of this restriction was noticed on subsequent daily weight gain, preventing any compensation of the delay in growth. However, the feed conversion ratio was depressed again in ad libitum fed gilts and a reverse trend appeared in barrows (interaction $\mathrm{S} \times \mathrm{A}_{1}, \mathrm{P}<0.10$ ).
\end{abstract}

At stage $A_{2}$, feeding the animals according to a schedule close to the ad libitum level resulted in higher growth rate ( 867 vs $825 \mathrm{~g} / \mathrm{d}$ ) and feed conversion ratio (2.95 vs 2.79 ) 